\title{
Assessing exposure to war-related traumatic events in older Vietnamese war survivors
}

\author{
Yvette Young ${ }^{1 *}$ (D), Kim Korinek', Zachary Zimmer ${ }^{2}$ and Tran Khanh Toan ${ }^{3}$
}

\begin{abstract}
Background: Though studies measuring war-related stressors and resultant trauma among U.S. military veterans are abundant, few studies address how wartime stressors affect military veterans native to warzones. Even fewer assess the stress exposure and resulting trauma experienced by Vietnamese civilians. This study aimed to construct a scale to quantify wartime stress exposure that is relevant for civilians and military veterans who survived the American War in Vietnam.

Methods: The study analyzed data from a novel source, the Vietnam Health and Aging Study, which surveyed older men and women residing in central and northern Vietnam. We used a combination of exploratory and confirmatory factor analysis with posthoc tests of reliability and validity to derive measures for assessing exposure to war-related traumatic events.

Results: We found that a mix of exposure to death, combat, inhospitable living conditions, and forced displacement comprises the traumatic events that potentially contribute to posttraumatic stress disorder and other mental health problems. However, the particular mix of stressful experiences constituting war trauma differs for civilians, veterans of the formal military, and former members of paramilitary organizations.

Conclusions: These findings suggest the need for distinct but parallel approaches to measuring war-related stressors for populations of veterans and civilians exposed to war in their home countries and the need for greater public attention to the potential lingering trauma of noncombatants.
\end{abstract}

Keywords: Combat, Nearness to death, Inhospitable conditions, Displacement, Posttraumatic stress disorder, Aging, Vietnam

\section{Background}

The last several decades have witnessed mounting empirical evidence demonstrating long-term deleterious health impacts of exposure to war-related traumatic events [1-3]. Mental health outcomes, such as posttraumatic stress disorder (PTSD) and depression, have received particularly intense attention and are perhaps best documented [4-6]. However, it is clear that war trauma associates with an extensive range of other adverse health outcomes and concerns that last throughout life. Lasting effects occur in diverse domains, including

\footnotetext{
* Correspondence: Yvette.Young@soc.utah.edu

${ }^{1}$ Department of Sociology, University of Utah, Salt Lake City, UT, USA

Full list of author information is available at the end of the article
}

health behaviors, functional health and disability, diagnosed chronic conditions, and general global wellbeing. These associations are either a function of the direct impact of the trauma experienced or effects mediated by other psychological causes such as PTSD [7-11].

Assessing precise direct and indirect impacts and possible interventions that may moderate their influences depends greatly on an ability to evaluate wartime experiences. Specifically, it is important to quantify the degree of trauma encountered and categorize traumatic experiences in meaningful ways (e.g., such that they can inform the relationship between war exposure and laterlife health). Ideally, such scales assessing exposure could be used by subsequent researchers.

(c) The Author(s). 2021 Open Access This article is licensed under a Creative Commons Attribution 4.0 International License, which permits use, sharing, adaptation, distribution and reproduction in any medium or format, as long as you give appropriate credit to the original author(s) and the source, provide a link to the Creative Commons licence, and indicate if changes were made. The images or other third party material in this article are included in the article's Creative Commons licence, unless indicated otherwise in a credit line to the material. If material is not included in the article's Creative Commons licence and your intended use is not permitted by statutory regulation or exceeds the permitted use, you will need to obtain permission directly from the copyright holder. To view a copy of this licence, visit http://creativecommons.org/licenses/by/4.0/ The Creative Commons Public Domain Dedication waiver (http://creativecommons.org/publicdomain/zero/1.0/) applies to the data made available in this article, unless otherwise stated in a credit line to the data. 
Since the mid-1980s, various approaches and instruments have been advanced to measure wartime exposure and related war stressors [6, 12-14]. Based on the diagnostic criteria for PTSD, particularly Criterion A, which qualifies traumatic exposure, existing scales tend to include items such as those that gauge threats and fear of death, being seriously injured, experiencing sexual violence, witnessing such events or threats to others such as fellow combatants, and experiencing other harmful physical conditions.

The preponderance of studies that have designed measures of war-related traumatic exposure $[5,6,12-15]$ focus on American veterans or veterans in other developed western countries fighting wars that occurred far from their communities of origin [16, 17]. Measures adopted to categorize and quantify wartime exposure have less frequently been assessed for use among populations living in places where wars actually ensue. Exposure to traumatic events within the latter groups is particularly salient in guerilla warfare situations or contemporary civil conflicts that unfold within villages, neighborhoods, and on roadways within urban and rural developing country settings. In these settings, potentially traumatic exposures might extend to death and injuries occurring among friends, relatives, and neighbors, the experience of being evacuated from one's home due to fear of oncoming violence, and fears that accrue to civilians and paramilitary personal as well as military combatants.

The case of the American-War fought in Vietnam presents an excellent opportunity to evaluate measures of wartime exposure for the purpose of examining longterm impacts of war. Those who experienced wartime trauma during this period (1965-1975) are moving into older ages, where the incidence and prevalence of chronic conditions and other health problems are heightened. The conflict they experienced was unusually brutal and was experienced by many different groups, including military personnel, paramilitary, and civilian women and men. In Vietnam, exposure among nonmilitary groups has rarely been identified, quantified, and categorized. Doing so requires access to retrospective data collected from cohorts of Vietnamese that lived through the war. This study uses a new and unique data source collected in 2018, the Vietnam Health and Aging Study (VHAS), with just such information. The VHAS surveyed 2447 individuals living in northern and central Vietnam that were differentially exposed to the American War, inquiring about their wartime experiences. Using these items, we aim to construct a scale to evaluate war-related stress exposure among the former members of formal military organizations, paramilitary groups (such as militias and the Youth Shock Brigades), and civilian populations of Vietnam. Such a scale would be valuable for studying the impacts of war-related trauma, specifically long-term health and other lifecourse outcomes. Service in informal military organizations, such as the Youth Shock Brigades (TNXP) and community militia groups, provided logistical and other support for formal military groups. The TNXP, or youth volunteer force, comprised young volunteers, including young women, who provided various forms of support to the war effort, from provision of weapons and foodstuffs to infrastructure repair and bomb disposal [18]. In many ways, their exposure to dangerous and traumatic events paralleled that of the formal military. However, they were also significantly less likely to exchange fire with the enemy. We compare exposures across these three groups that encountered an assortment of different wartime conditions and experiences.

\section{Defining traumatic events}

Measuring the exposure to traumatic events that precede the experience of trauma and resultant mental and physical health issues requires a clear definition of "traumatic events." The American Psychiatric Association (APA) defines trauma as "an emotional response to a terrible event like an accident, rape or natural disaster" [19]. The "terrible events" of import for this study are war-related traumatic events and stressors. ${ }^{1}$ Researchers have long struggled to understand the precise features of traumatic stressors [20-22]. Weathers and Keane [22] note that crafting a definition of trauma and traumatic events is difficult, in part, due to the many relevant dimensions of stressors, including their "magnitude (which itself varies on several dimensions, e.g., life threat, threat of harm, interpersonal loss ... ), complexity, frequency, duration, predictability, and controllability" [22]. As such, most researchers rely on descriptions of traumatic events contained in the diagnostic criteria for PTSD $[6,22,23]$. The clinical definition and diagnostic, found in the current version of the Diagnostic and Statistical Manual of Mental Disorders (DSM-5), lays out five criteria for diagnosing PTSD. The first criterion, without which there can be no diagnosis, is exposure to a traumatic event [22, 24, 25]. Specifically, Criterion A requires: "[e] xposure to actual or threatened death, serious injury, or sexual violence," by directly experiencing or witnessing the traumatic events or learning about the traumatic experiences of family and close friends ${ }^{2}$ [24]. In this paper, we follow previous scholars in relying on the description of traumatic stressors provided in the DSM-5, specifically being wounded, seriously injured, or almost killed; witnessing acts of injury and killing; and learning about the death and injury of family members. ${ }^{3}$ We supplement the events outlined in Criterion A with war-related

\footnotetext{
${ }^{1}$ We use the terms terrible event, traumatic event, and traumatic stressor interchangeably throughout the paper.
} 
stressors validated by previous scholars, including engaging in combat duties, exposure to inhospitable conditions, and witnessing the effects of war violence. We also test new stressors for their potential relevance to the Vietnam context.

\section{Existing warzone stress scales}

Two broad research domains have investigated warrelated traumatic stressors and how to measure them. One domain focuses on war veterans, while the other centers on refugees.

Prior research into traumatic events experienced by veterans has identified stressors clustering in four dimensions: combat activities, nearness to death and severe injury, moral injury, and inhospitable conditions $[12,13,26]$. However, most researchers did not include all four dimensions in their scales. For many veterans, especially those deployed to combat duties, some exposure to death and serious injury, whether to oneself or others, is practically a foregone conclusion. As such, early scales, like the National Vietnam Veterans Readjustment Study (NVVRS) and Combat Exposure Scale (CES), measured exposure to war-related violence by cataloging combat experiences $[6,14,27]$. However, scholars also recognized that war-related exposure to traumatic events extends beyond mere combat exposure. For example, war-related trauma can extend to morally injurious experiences, or the "harm received to one's moral center" [28] as a result of "perpetrating, failing to prevent, bearing witness to, or learning about acts that transgress deeply held moral beliefs and expectations" [29]. Personal "moral injury" can occur when one takes another's life, commits or witnesses the commission of atrocities, or fails to prevent the suffering of civilians or fellow service members [5, 25, 29-31]. Laufer and his colleagues tested a model of war-related trauma that added the moral-injury dimensions of witnessing abusive violence and participating in abusive violence to the typical combat experiences items. This scale was innovative in that it accounted for the guerilla-style of warfare characteristic of the Vietnam War. Laufer's subjects reported stress related to their inability to "distinguish between noncombatants and the enemy," "sanctioned acts of brutality," and the use of "cruel weapons" [15].

Scholars have also documented the role inhospitable living conditions play in trauma exposure [5, 14, 25]. Using their Deployment Risk and Resilience Inventory (DRRI) [13], King et al. [25] found that among American veterans of the Vietnam War, exposure to a "malevolent

\footnotetext{
${ }^{2}$ See Supplementary file 1: Appendix A for the complete text.

${ }^{3} \mathrm{We}$ did not include sexual assault due to severe under-reporting. Only 7 respondents, or $0.6 \%$ of all women, indicated that they had been sexually assaulted during the war. The question was not asked of men.
}

environment" (i.e., the undesirable food, climate, living conditions, and other chronic, lower-magnitude stressors of warzone deployment) was the most pronounced contributor to PTSD, far surpassing the influence of combat. However, for civilians and local military residents of warzones, the conditions constituting "malevolent" or inhospitable living environs likely differ from those enumerated by veterans of foreign wars, a theme investigated in research on trauma in refugees.

The second domain of trauma research focuses on sources of trauma for refugees, asylees, and displaced persons. This branch of research often omits combat-related inquiries in favor of war-related stressors that anyone might experience, but it adds new dimensions of stressors, including mental injury, extrajudicial operations, and displacement. In addition, this body of work adds breadth to dimensions of trauma investigated with veterans.

A notable omission in measurement scales designed for veterans is the lack of attention to evacuation and other "less than voluntary" migration experiences. This oversight likely stems from the fact that prior research focused primarily on American veterans of foreign wars. However, refugee scholarship informs us that warrelated forced migration is concurrent with exposure to other traumatic events and dangers typically associated with warzones. Moreover, forced migration has been associated with subsequent mental distress [32-34] and may connect directly and indirectly to posttraumatic stress. To illustrate the complexity of the relationship between displacement as a traumatic event and mental health, Porter and Haslam [35] describe how refugees experience stress accumulating at multiple different stages of displacement, including preflight, flight, exile, and resettlement or repatriation.

This study integrates the insights of two research domains, evaluating the dimensions of stressful wartime events for use as trauma exposure indicators in northern Vietnamese survivors of the American war. We draw from prior research, combining items from prior scales to investigate these dimensions. We include items related to combat activities, personal and family injury and death, witnessing death and severe injury, moral injury, inhospitable conditions, and displacement. Two recent studies noted that some scales clustering combat activities, injury, and nearness to death into distinct groups demonstrated poor divergent validity $[12,26]$. As such, we anticipate that the events may cluster differently than previously thought. We also test whether the dimensionality is consistent across civilians, informal military, and formal military respondents. Finally, the two principal research domains primarily (though not exclusively [17]) study people who no longer reside in the location where they were exposed to conflict, i.e., veterans of foreign wars and refugees resettled outside the warzone. Our 
study seeks to integrate the two conceptual domains and fill this critical gap in the research [16], investigating the nature of warzone stressors for residents of Vietnam, subgroups of which include civilians, veterans of the formal military, and paramilitaries and others peripherally involved in war efforts.

\section{Method}

\section{Data and sample}

This paper analyzes data from the Vietnam Health and Aging Study (VHAS), collected in face-to-face interviews conducted in 2018. The VHAS was designed to investigate the long-term effects of exposure to war, specifically, the American War, on older adult physical and mental health, overall wellbeing, and mortality. VHAS investigators used a multistage, stratified probability design to sample 2447 men and women aged $60+$ in four districts of northern and central Vietnam. This age group was chosen because it encountered the height of the American War (1965-1975) during childhood, adolescence, and early adulthood. The American War in Vietnam was characterized by unprecedented levels of bombing, widespread defoliation, and extensive population displacement $[36,37]$. The war also generated considerable military recruitment and mobilization efforts [38]. The four districts sampled - Bavi, Yen Khanh, Dong Hoi, and Bo Trach-were purposively-selected to represent a spectrum of war exposure, as indicated by the intensity of bombings during war years [39, 40]. ${ }^{4}$ Within these districts, investigators randomly selected 12 communes, after which they randomly selected 204 individuals from each commune (see 39 for additional details). Men and women with both formal and informal military service were included in the sample, as were nonveterans.

\section{Measures}

Our study's measures derive from VHAS questions about respondents' military participation, death and disability among family members, diverse forms of war exposure, and PTSD. The questions are shown in their entirety in Supplementary file 1: Appendix C.

\section{Group variable-military participation}

Concerning military participation, the survey asked: "Have you ever participated in any military activities?" Response options included: served in the formal military (Viet Minh, before 1954), served in the formal military (People's Army of North Vietnam), served in the formal military (Army of the Republic of Vietnam), and served in the Youth Shock Brigade (Thanh niên xung phong or

\footnotetext{
${ }^{4}$ Bombing intensity data provided by Miguel and Roland [40]. See Figure 1 in Supplementary file 1: Appendix B.
}

TNXP), and involved in other militia services. We grouped the formal military service responses into a formal military category and combined service in the TNXP and militia into an informal military category.

\section{Death and disability of family members}

Reflecting conceptual and operational definitions of traumatic stressors ${ }^{5}$ described above, we included items assessing deaths, severe injury, and disability of family members due to the war [14]. ${ }^{6}$ Familial experiences of war-related death and disability were assessed separately for the respondent's father, mother, brother(s), sister(s), spouse, and children.

\section{War exposure variables}

The VHAS survey contained question sets assessing four types of trauma exposure referenced in prior studies: nearness to death and severe injury, inhospitable conditions, and combat experiences, including moral injury. VHAS investigators drew from NVVRS [14], DRRI [13], and CES [6] to design war exposure items. Nearness to death items included questions about seeing dead or seriously injured Vietnamese soldiers, foreign soldiers, and civilians; and questions about being injured and knowing people injured or killed in battle. Items gauging exposure to inhospitable conditions included questions documenting displacement due to village bombings or evacuations and questions regarding shortages of clean water and food, inability to sleep due to noise or inhospitable conditions, fearing being injured or killed, and exposure to toxic chemicals, including agent orange.

The combat experience questions-asked only of respondents with formal or informal military experience ${ }^{7}$-inquired about eight combat experiences. These questions assessed how many times the respondent experienced going on patrols, being ambushed, coming under artillery fire, firing at the enemy, being responsible for the death of the enemy, being nearly shot, and having friends shot near them in battle.

\section{PTSD variables}

The VHAS includes nine questions, drawn from the 20item PTSD Checklist for the DSM-5 (PCL-5), assessing respondents' experience of PTSD. These asked whether the respondent had experienced a specified form of stress and how much it bothered them. Questions tapped the respondents' level of re-experiencing

\footnotetext{
${ }^{5}$ See Item 3 of Criterion A in Supplementary file 1: Appendix A. ${ }^{6}$ See Supplementary file 1: Appendix $C$ for a question wording and recoding methods for all items.

${ }^{7}$ Militia and TNXP members often encountered combat-like conditions. Thus, questions regarding combat experiences were posed to veterans of the formal military, as well as members of the TNXP and other militias.
} 
traumatic events, avoiding reminders, emotional numbing, arousal, and anxiety. Only nine questions were incorporated, in part, to reduce respondent burden. In addition, VHAS investigators removed questions that did not translate well, either linguistically or culturally, to the Vietnam context or were politically sensitive. Reduced scales, some with as few as two items, have been previously validated by scholars seeking to apply the scale internationally [41-43]. Lang et al. [41] compared abbreviated scales with the full PCL and clinician diagnoses, finding that longer abbreviated scales performed better than short ones. As such, we used all items available to us in the VHAS.

\section{Data analysis}

The purpose of this study was to establish a scale quantifying stressful war experiences that is valid for veterans of both formal and informal military organizations, as well as civilians in Vietnam. Because the survey combined items from scales previously used solely with veterans assessing both combat and noncombat experiences, with items designed to assess trauma exposure in civilians, it was necessary to evaluate how these questions hang together as indicators of stressful war experiences. To that end, we conducted exploratory factor analysis (EFA), comparing results across civilians, informal military, and formal military, followed by confirmatory factor analysis (CFA). To account for the fact that some items were binary while others contained multiple categories, we recoded all into binary indicators, which reduces method effect biases $[44,45]$. To account for the fact that some questions were not asked of civilians, we tested separate models for civilians, informal military, and formal military.

The unique VHAS sampling approach required that we use survey estimation methods and apply sampling weights. ${ }^{8}$ However, many statistical operations limit the application of survey-estimation techniques and sampling weights. In addition, binary variables require special treatment in factor-analytic models, specifically, analysis based on tetrachoric correlations. Thus, our analysis proceeded in three broad steps: 1) preliminary inspection of the tetrachoric correlation matrix, 2) estimation of weighted tetrachoric EFA using the iterated principal factors (IPF) ${ }^{9}$ method with oblique rotation, ${ }^{10}$ 3) examination of survey-adjusted CFA with sampling weights. ${ }^{11}$ All analyses were conducted in Stata version 15.

\footnotetext{
${ }^{8}$ Our survey estimation specified the commune as the primary sampling unit (PSU) and the district as the strata. Survey estimation calculates robust standard errors while accounting for the clustering of errors within strata and PSUs.
}

We undertook step one following DeVellis' [50] recommendations, who argues that scale items must be highly intercorrelated. Tetrachoric correlations were used to compensate for the artificially-binary structure of our scale items [51]. We engaged in multiple iterations of weighted tetrachoric EFA, step two, to assess item clustering and make a preliminary determination regarding the appropriate number of factors via eigenvalues, scree tests, and parallel analysis. When clear factor structures were not apparent, we compared alternate model specifications, preferring models with the cleanest factor loadings (i.e., strong loadings, no cross-loadings, and multiple items per factor). Table 1 details our retention criteria. Finally, we used survey adjusted, weighted CFA to refine and confirm the relational structure of the factors (e.g., relationship between factors, subdimensions, etc.) and evaluate theoretically-relevant correlations between item error terms.

To assess model fit, we evaluated the Kaiser-MeyerOlkin (KMO) measure of sampling adequacy, root mean squared error of approximation (RMSEA), standardized root mean squared residual (SRMR), and comparative fit index (CFI). Our goodness of fit (GOF) criteria are shown in Table 2. To confirm the appropriateness of scales derived from our factor analysis, we evaluated reliability and validity using coefficient omega, ${ }^{12}$ composite factor reliability $(\mathrm{CR}){ }^{13}$ average variance extracted (AVE),

squared correlations between factors (SC), and the correlation of factors with PTSD. The purpose of each measure and the criteria for establishing reliability or validity are shown in Table 2 .

\section{Results}

The analytical sample for this study included 1195 men and 1252 women. In all, $43 \%$ of respondents engaged in

\footnotetext{
${ }^{9} \mathrm{IPF}$ generates multiple iterations of the squared multiple correlation coefficients to first estimate and then refines the estimation of communalities. Although many scholars recommend maximum likelihood estimation for its handling of missing data, our data contain very few missing values. Moreover, IPF is preferred over maximum likelihood when items are not normally distributed [46, 47]. Since our items are binary we employed IPF rather than maximum likelihood estimation.

${ }^{10}$ We used quartimin normalized (oblique) rotation after Stata's factor command. Oblique rotation accounts for the fact that the items and standard errors are correlated. Quartimin "maximizes the variance of the squared loadings within the variables" with oblique rotations [48], based on Harman's quartimax criterion [49].

${ }^{11}$ The models, estimated using Stata's sem command which allows for estimation with binary variables, were run using survey estimation techniques and sampling weights.

${ }^{12}$ Coefficient omega estimates the composite reliability using factor loadings and uniqueness, a method which, unlike Cronbach's alpha, is unbiased when items are congeneric and errors are uncorrelated [56].

${ }^{13}$ Composite reliability was calculated using the tetrachoric correlation matrix to ensure its relevance for the binary data.
} 
Table 1 Factor Retention and Composition Criteria

\begin{tabular}{llll}
\hline & Step & Purpose & Criteria \\
\hline Factor (F) Retention & & & $\geq 1.0$ \\
Eigenvalue & 2 & Variance explained by F & Elbow location [52] \\
$\begin{array}{l}\text { Scree Test } \\
\text { Parallel Test }\end{array}$ & 2 & F Strength/relevance & Line intersection \\
Factor Correlation & 2 & F Strength/relevance & $<0.85[44,53]$ \\
Factor Composition & $2-3$ & F Distinctiveness & $\geq 0.3[50]$ \\
Correlation & & & $\geq 0.4^{1}[50]$ \\
Loadings & 1 & Sufficient association & Diff. $>0.5[46,50,51]$ \\
Crossloading & $2-3$ & Item determinacy & $>2[44,50,51]$ \\
\# Items per factor & $2-3$ & Item distinctiveness & $\leq 0.6[44,50]$ \\
Uniqueness & $2-3$ & Model identification & Proportion unexplained by F \\
\hline
\end{tabular}

military activities during the war, with $56 \%$ of men and $34 \%$ of women reporting military activities. ${ }^{14}$ Nineteen percent were members of the formal military, while $24 \%$ participated in informal military activities such as the militia or TNXP. Sixty-nine percent experienced at least one war-specific stressor exposure. Among those with military service, a notable $50 \%$ reported no exposure to stressful combat experiences. However, 55\% did not serve in the formal military and thus may have served in support rather than combat positions. Table 3 summarizes war-related stressor exposures.

The weighted tetrachoric correlation matrix showed strong correlations (above 0.3) between all items in the expected groups. Several of the combat and nearness to death items also correlated with shortages of clean water, exposure to toxic chemicals, and experiencing fear of death, indicating potential cross-loading items, requiring clarification via factor analysis. Inhospitable living conditions and war-related migrations also demonstrated the expected correlations plus potential crossloading correlations. When computed separately for civilians, informal military, and formal military, the correlation matrices showed that correlation patterns varied between the three groups, potentially warranting separate analyses. ${ }^{15}$ We examined these patterns further using weighted tetrachoric EFA with oblique rotation followed by weighted CFA.

In preliminary tests using EFA models, we discovered that although death and disability of family members clustered strongly into two respective factors, the factors

Table 2 Goodness of Fit Criteria

\begin{tabular}{|c|c|c|c|}
\hline & Step & Purpose & Criteria \\
\hline \multicolumn{4}{|l|}{ GOF $^{2}$} \\
\hline $\mathrm{KMO}$ & 2 & Sampling adequacy & $\geq 0.7$ \\
\hline RMSEA & 3 & General fit - model parsimony & $\leq 0.08[44,54]$ \\
\hline SRMR & 3 & Diff. between sample \& model & $\leq 0.08[55]$ \\
\hline $\mathrm{CFI}^{3}$ & 3 & General fit - Comparative fit & $\geq 0.95[54,55]$ \\
\hline \multicolumn{4}{|l|}{ Appropriateness } \\
\hline \multicolumn{4}{|l|}{ Reliability } \\
\hline Omega & 3 & Internal reliability & $\geq 0.7[56]$ \\
\hline$C R$ & 3 & Composite reliability & [57] \\
\hline \multicolumn{4}{|l|}{ Validity } \\
\hline AVE & 3 & Convergent validity & $\geq 0.5$ or $>$ CR $[58,59]$ \\
\hline SC & 3 & Discriminant validity & AVE > SC [57] \\
\hline Corr. with PTSD & 3 & Construct validity ${ }^{4}$ & $p \leq 0.05[50,51,60]$ \\
\hline
\end{tabular}

${ }^{1}$ We retained items with loadings between 0.3 and 0.4 when there were strong theoretical reasons for keeping the item [61]

${ }^{2}$ Chi-square statistics are not reported as they are not applicable with binary data [44]

${ }^{3}$ The Tucker-Lewis index (TLI) is not shown as it is prone to bias and model misspecification with binary data [54]

${ }^{4}$ All of the war-related events included, with the exception of inhospitable conditions, meet Criterion A's definition of traumatic events, demonstrating content validity. Correlations further show that the events we have assumed to be traumatic are, in fact, associated with trauma, demonstrating construct validity 
Table 3 Descriptive Statistics (percent reporting having had the experience at least once) ${ }^{a}$

\begin{tabular}{|c|c|c|c|c|c|}
\hline & All Rs & $\begin{array}{l}\text { Civilians } \\
\text { (C) }\end{array}$ & $\begin{array}{l}\text { Informal } \\
\text { Mil (I) }\end{array}$ & Formal Mil (F) & Significant Differences between Groups \\
\hline Family Death/Disability & 51.4 & 51.1 & 56.6 & 45.9 & I vs. F \\
\hline Death of family member & 32.5 & 33.7 & 34.8 & 26.1 & \\
\hline Disability of family member & 27.6 & 22.1 & 33.6 & 27.4 & \\
\hline Witness Death/Severe Injury & 48.5 & 35.6 & 52.4 & 80.8 & C vs. F; I vs. F \\
\hline Saw dead Vietnamese soldiers & 35.2 & 19.2 & 40.0 & 75.6 & C vs. I; C vs. F; I vs. F \\
\hline Saw dead foreign soldiers & 16.0 & 5.8 & 16.3 & 44.9 & C vs. I; C vs. F; I vs. F \\
\hline Saw dead civilians & 40.7 & 31.6 & 47.2 & 58.8 & C vs. F; I vs. F \\
\hline Wounded in warzone & 11.1 & 1.9 & 9.7 & 39.3 & C vs. I; C vs. F; I vs. F \\
\hline Know injured people & 31.8 & 20.7 & 39.5 & 54.8 & C vs. I; C vs. F; I vs. F \\
\hline Inhospitable Conditions & 59.7 & 51.6 & 66.0 & 75.7 & C vs. I; C vs. F \\
\hline Moved due to bombings & 22.8 & 20.5 & 27.6 & 23.6 & \\
\hline Moved due to evacuation & 21.3 & 20.1 & 22.8 & 23.1 & \\
\hline Shortage of clean water & 11.5 & 7.5 & 12.3 & 22.3 & C vs. F; I vs. F \\
\hline Food shortage & 20.4 & 17.6 & 22.0 & 26.7 & \\
\hline Inability to sleep & 36.4 & 30.3 & 41.9 & 47.2 & C vs. F \\
\hline Fear being injured or killed & 32.4 & 30.3 & 38.9 & 30.7 & \\
\hline Exposure to toxic chemicals & 7.5 & 2.2 & 5.2 & 25.5 & C vs. I; C vs. F; I vs. F \\
\hline Combat Experiences $^{c}$ & 21.6 & - & 31.0 & 73.5 & I vs. F \\
\hline Went on military patrols & 17.0 & - & 21.2 & 63.2 & I vs. F \\
\hline Was ambushed & 11.1 & - & 8.6 & 47.7 & I vs. F \\
\hline Came under artillery fire & 12.3 & - & 10.9 & 51.1 & I vs. F \\
\hline Shot at the enemy & 10.5 & - & 4.9 & 49.2 & I vs. F \\
\hline Caused death of enemy & 6.5 & - & 1.8 & 32.0 & I vs. F \\
\hline Was nearly shot & 9.4 & - & 10.6 & 36.6 & I vs. F \\
\hline A friend was shot & 11.0 & - & 8.8 & 46.9 & I vs. F \\
\hline
\end{tabular}

Weighted percentages shown

${ }^{\mathrm{b}}$ Significance tested via binary logistic regression (survey adjusted, with sampling weights) with marginal predictions and confidence intervals using a significance level of 0.05 . Bold indicates that a group is significantly different from all other groups

'These questions were only asked of people who participated in military activities. Proportions for informal and formal military are based on veterans only

were largely unrelated to other stressful war experiences. Additionally, the death and disability of family members items are conceptually and chronologically distinct from the other major war-related stressors (i.e., they may have occurred when the respondent was quite young and could not recall; or may have occurred during earlier wars for which we lack other war stressor measures). As a result, we removed these items from all models.

Our first set of models, analyzing civilian respondents, yielded three factors: exposure to war violence (VIOL), inhospitable conditions (COND), and war-related

\footnotetext{
${ }^{14}$ We report survey-adjusted, weighted descriptive statistics in the main text. For comparison, when unweighted, $66.3 \%$ of our sample reported some type of military service, with $40.3 \%$ reporting formal military service and $26.1 \%$ reporting participation in informal military activities.

${ }^{15}$ Our preliminary CFA modeled factors by group confirming significant differences between groups.
}

migration (MOVE). In EFA, the eigenvalues and the scree test indicated two factors. ${ }^{16}$ However, the twofactor model had cross-loading items indicating either that more factors were needed or that the cross-loading items were not relevant to the factors. We tested models with 1, 2, 3, and 4 factors. The 3-factor model was the only model to meet all factor composition criteria. It also made the most sense theoretically and was confirmed in CFA, with one substantive difference-the COND and MOVE factors were shown to function as sub-dimensions of a broader wartime environment (ENV) factor. Figure 1 shows the relational structure of these factors.

The war violence factor included seeing dead or seriously injured Vietnamese and foreign soldiers, seeing

\footnotetext{
${ }^{16}$ Parallel test values never rose above the eigenvalues, making it uninformative.
} 
dead or seriously injured civilians, and being wounded in the warzone. Knowing people who were injured was removed from the factor during CFA due to its high unique variance. This factor captures experiences related to being the victim of violence, witnessing violence, or witnessing the effects of violence. The inhospitable conditions factor included experiencing shortages of food and clean water, and the inability to sleep due to noise and other inhospitable conditions. The migration factor included three items: moving due to bombings and evacuations, and exposure to toxic chemicals. The wartime environment factor encompasses both displacement and inhospitable living conditions confirming the close relationship between these two sets of items. Table 4 presents factor loadings.

The civilian model demonstrated acceptable goodness of fit $(\mathrm{KMO}=0.77 ; \mathrm{RMSEA}=0.05 ; \mathrm{CFI}=.95)$, and all factors demonstrated acceptable internal reliability (omega $\geq 0.7$ ). All factors also exhibited convergent validity with AVE values greater than 0.5 and discriminant validity. See Table 5 for reliability and validity statistics. Also, correlations between predicted factors and PTSD indicate that the factors are indeed associated with the theoretically-related phenomenon, PTSD, demonstrating construct validity.

The second set of models, analyzing informal military respondents, yielded two factors: exposure to combat conditions and related violence (COMBAT) and inhospitable conditions and displacement (COND). In EFA, the eigenvalues and the scree test indicated two factors. ${ }^{17}$ However, the two-factor model had cross-loading items indicating either that more factors were needed or that the cross-loading items were not relevant to the factors. We compared models with 1, 2, 3, and 4 factors. None of the models improved the factor composition statistics. Moreover, the 2-factor model made the most sense theoretically. We revised the 2-factor model, removing Know people who were injured due to low loadings and high uniqueness, and removing Saw dead Vietnamese soldiers and Saw dead civilians due to crossloading with nearly equivalent values on both factors. At this stage, we retained Fear of death/severe injury despite high uniqueness because it had adequate factor loadings, and there are strong theoretical reasons for retaining it. In CFA, we found extremely low factor loadings and high unique variances for Exposed to toxic chemicals and Fear of death/severe injury. When retaining these items, model fit statistics were poor, and removal of the items improved RMSEA, SRMR, and CFI, raising them to acceptable levels. However, the convergent validity of COMBAT was below acceptable levels $(\mathrm{AVE}=0.47)$. Removal of two additional items (Shot at the enemy and Caused death of an enemy) exhibiting low equation-level $r$-squared values improved convergent validity and further improved the model's goodness of fit. Figure 2 shows the final structure of these factors for respondents with an informal military background.

The combat factor included being wounded in the warzone, going on combat patrols, being ambushed, coming under artillery fire, shooting at the enemy, nearly being shot, and having a friend shot near them in battle. This factor primarily captures experiences related to engaging in the formal activities of war. The inhospitable conditions factor included moving due to bombing or evacuation and experiencing food shortages. Exposure to toxic chemicals, shortages of clean water, and the inability to sleep failed to load on the factor in CFA. See Table 4 for factor loadings.

The informal military model demonstrated acceptable goodness of fit $(\mathrm{KMO}=0.78$; RMSEA $=0.03 ; \mathrm{CFI}=0.99)$, and all factors demonstrated acceptable internal reliability (omega $\geq 0.87$ ). All factors also exhibited convergent validity with AVE values greater than 0.5 and discriminant validity. See Table 6 for reliability and validity statistics. In addition, correlations indicate that the predicted factors were again associated with PTSD, exhibiting construct validity.

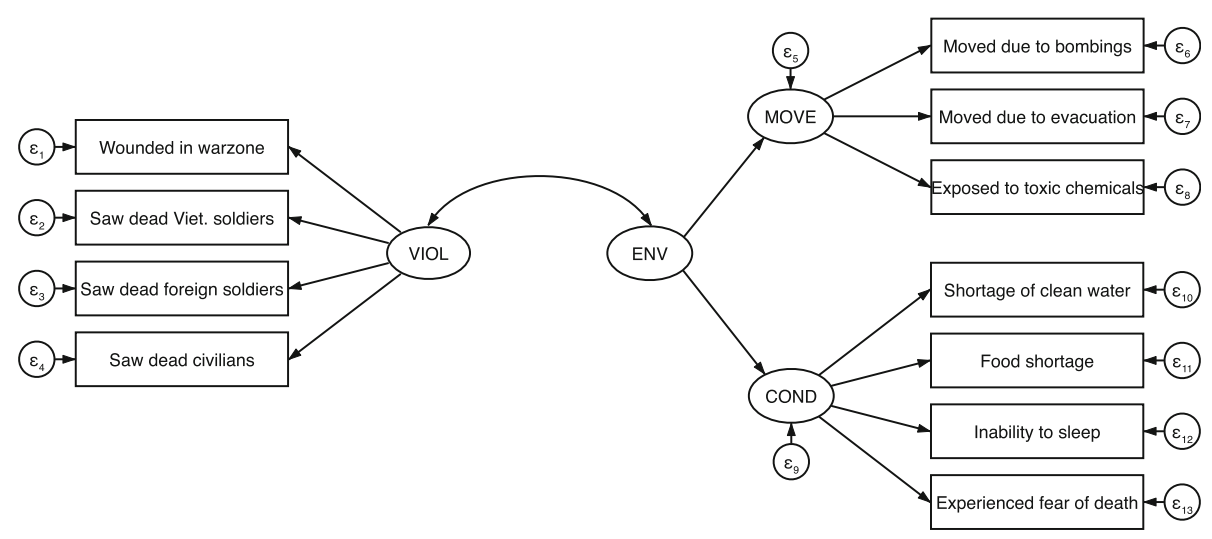

Fig. 1 Factor Structure of War-related Traumatic Events for Civilians 
Table 4 Factor Loadings for All Models

\begin{tabular}{|c|c|c|c|}
\hline & Civilians & Informal Mil. & Formal Mil. \\
\hline VIOL and COMBAT Factors & VIOL & COMBAT & COMBAT \\
\hline Wounded in warzone & 0.620 & 0.617 & 0.673 \\
\hline Know people who were injured & & & 0.614 \\
\hline Saw dead Vietnamese soldiers & 0.991 & & 0.911 \\
\hline Saw dead foreign soldiers & 0.823 & 0.560 & 0.737 \\
\hline Saw dead civilians & 0.816 & & \\
\hline Went on combat patrols & - & 0.636 & 0.828 \\
\hline Was attacked/ambushed & - & 0.769 & 0.829 \\
\hline Came under artillery fire & - & 0.824 & 0.889 \\
\hline Shot at the enemy & - & & 0.898 \\
\hline Caused death of an enemy & - & & 0.842 \\
\hline Was nearly shot & - & 0.828 & 0.693 \\
\hline Friend was shot near $\mathrm{R}$ & - & 0.726 & 0.830 \\
\hline MOVE and COND Factors & MOVE & COND & COND \\
\hline Exposed to toxic chemicals & 0.549 & & \\
\hline Moved due to bombings & 0.792 & 0.948 & \\
\hline \multirow[t]{2}{*}{ Moved due to evacuation } & 0.642 & 0.947 & \\
\hline & COND & & \\
\hline Shortage of clean water & 0.962 & 0.615 & 0.836 \\
\hline Food shortage & 0.866 & 0.552 & 0.926 \\
\hline Inability to sleep & 0.469 & & 0.563 \\
\hline Fear of death/severe injury & 0.481 & & \\
\hline ENV Factor & ENV & & \\
\hline COND & 0.848 & - & - \\
\hline MOVE & 0.797 & - & - \\
\hline $\mathrm{N}$ & & 598 & 942 \\
\hline
\end{tabular}

Our final set of models, analyzing formal military respondents, also yielded two factors: exposure to combat conditions and related violence (COMBAT) and inhospitable conditions (COND). In EFA, the eigenvalues and the scree test indicated three factors. ${ }^{18}$ The 3 -factor model had one item (Moved due to bombings) with a negative uniqueness value, indicating that this solution was a Heywood Case. Factor 3 contained only two items

Table 5 Model Evaluation Statistics — Civilians

\begin{tabular}{|c|c|c|c|c|c|}
\hline & Criteria & VIOL & COND & MOVE & ENV \\
\hline \multicolumn{6}{|l|}{ Reliability } \\
\hline Omega & $\geq 0.7$ & 0.89 & 0.80 & 0.70 & 0.87 \\
\hline$C R$ & & 0.58 & 0.61 & 0.60 & 0.47 \\
\hline \multicolumn{6}{|l|}{ Validity } \\
\hline AVE & $\geq 0.5$ or $>C R$ & 0.68 & 0.53 & 0.56 & 0.50 \\
\hline SC & $A V E>S C$ & $0.31 ; 0.35$ & $0.31 ; 0.26$ & $0.35 ; 0.26$ & 0.12 \\
\hline Corr. w/ PTSD & $p \leq 0.05$ & $0.31^{*}$ & $0.32^{*}$ & $0.18^{*}$ & $0.31^{*}$ \\
\hline
\end{tabular}

making it "just" identified, thus the possible source of the Heywood solution (Chen 2001). We tested alternate 1- and 2-factor solutions. The 1-factor model exhibited high uniquenesses on all items related to moving and inhospitable conditions, making it a less appropriate solution. In the 2-factor model, Fear of death/severe injury failed to load on either factor; it was removed from the final EFA model. While Exposed to toxic chemicals had a somewhat low loading on Factor 1 (0.36) and very high uniqueness $(0.81)$, it was retained due to theoretical relevance. In CFA models, Moved due to bombings exhibited problematic uniqueness levels, ${ }^{19}$ and when removed, Moved due to evacuation had a very high unique

\footnotetext{
${ }^{17}$ Parallel test values again failed to rise above the eigenvalues, making the test uninformative.

${ }^{18}$ Parallel test values again failed to rise above the eigenvalues, making the test uninformative.

${ }^{19}$ The uniqueness was near zero, indicating a Heywood case likely stemming from model misspecification [62]. Removing the item clarified more appropriate solutions.
} 


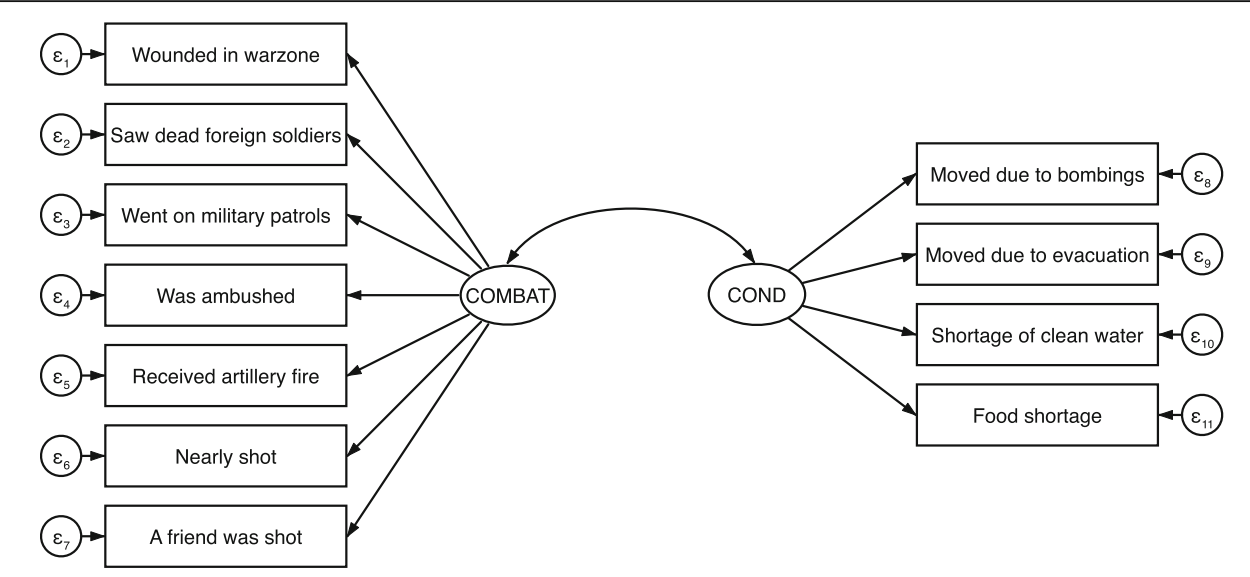

Fig. 2 Factor Structure of War-related Traumatic Events for Participants in Informal Military Activities

variance (0.90). Saw dead civilians and Exposed to toxic chemicals also demonstrated high unique variances (above 0.80). Removing the four problematic items improved all goodness of fit statistics. Figure 3 shows the relational structure of these factors.

The COMBAT factor included a mix of variables related to being the victim of violence, witnessing violence and its effects, and engaging in combat activities. The inhospitable conditions factor included experiencing shortages of food and clean water, and the inability to sleep due to noise and other inhospitable conditions. However, the factor failed to include war-related displacement. See Table 4 for factor loadings.

The formal military model demonstrated acceptable goodness of fit $(\mathrm{KMO}=0.92$; RMSEA $=0.04 ; \mathrm{CFI}=0.98)$, and all factors demonstrated acceptable internal reliability (omega $\geq 0.83$ ). All factors also exhibited convergent validity with AVE values greater than 0.5 and discriminant validity with factor convergence greater than the squared correlation between factors. Table 7 shows the model's reliability and validity statistics. Finally, correlations between predicted factors and PTSD indicate that the factors are again associated with PTSD, demonstrating construct validity.

Table 6 Model Evaluation Statistics — Informal Military Model

\begin{tabular}{llll}
\hline & Criteria & COMBAT & COND \\
\hline Reliability & & & \\
Omega & $\geq 0.7$ & 0.88 & 0.86 \\
CR & & 0.50 & 0.67 \\
Validity & & & \\
AVE & $\geq 0.5$ or $>$ CR & 0.51 & 0.62 \\
SC & AVE $>$ SC & 0.09 & 0.09 \\
Corr. W/ PTSD & p $\leq 0.05$ & $0.33^{*}$ & $0.32^{*}$ \\
\hline
\end{tabular}

\section{Discussion}

The goal of this study was to explore a set of war-related stress exposures to identify items that, together, act as a scale quantifying exposure to war-related traumatic events in a sample of older Vietnamese men and women currently residing in Northern or North Central Vietnam. Our intent was to develop a scale that is valid in the Vietnam context and would allow future researchers to investigate the long-term effects of said war-exposure for civilians, formal military, and paramilitary alike. In pursuing this goal, we integrated insights of two scholarly domains: trauma research focusing on veterans and that focusing on refugees and other civilian residents of warzones. As a result, our study yields novel information on the content of war-related stress for survivors of war in diverse post-conflict contexts outside of the widely studied U.S. veteran population.

Four findings are important to highlight: 1) Some common predictors of PTSD, which may occur during wartime, are not components of war-related trauma exposure; 2) Items from prior instruments did not operate as distinct factors or subscales, rather they clustered with items from other instruments; 3) The contributions of both domains of trauma research-veterans studies and refugee studies-are relevant for studying trauma in residents of warzones; and finally, 4) Civilians, members of militias and other less formalized military organizations, and members of formal military organizations, experience war events differently, indicating the need for distinct measurement approaches.

\section{War trauma versus general trauma}

One common predictor of PTSD, witnessing or learning of the violent or accidental death or severe injury of a family member(s), is a likely occurrence among those who live in warzones. Prior research has shown a strong correlation between these experiences and PTSD or 


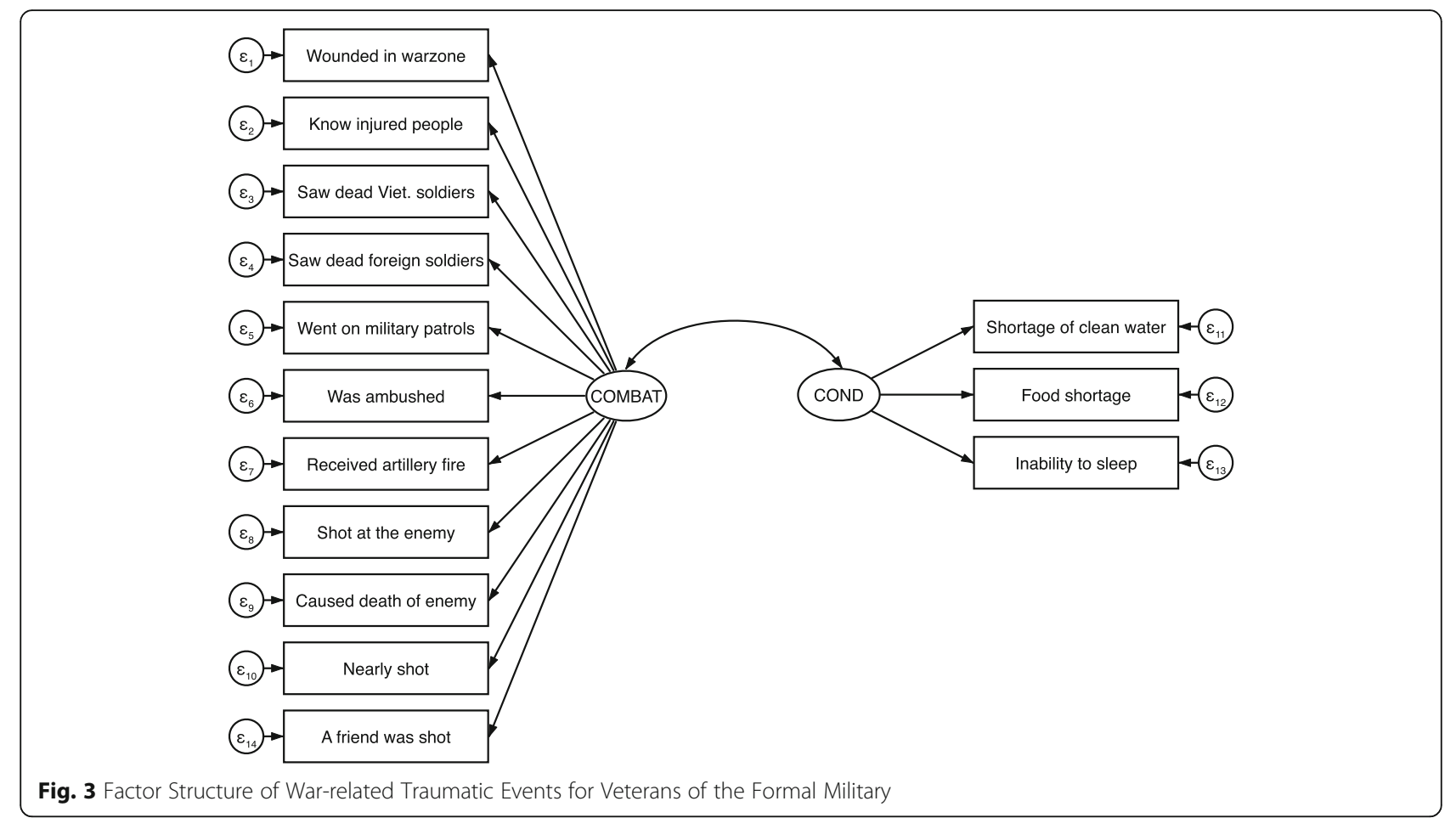

other forms of mental distress $[63,64]$. However, in the VHAS sample, the correlation is very weak, ranging from 0.08 to 0.14 . Moreover, the DSM-5 enumerates the "violent or accidental" death of family and friends as traumatic events in Criterion A. Our study found that while the death and disability of family members may contribute to PTSD, this form of exposure does not cluster with other war-exposure items. This may indicate that death and disability of family members, however linked to war, is distinct from other war-related trauma exposures and should not be included in scales designed to measure war-related trauma exposure. Alternately, it may reflect the secondary (as opposed to first-hand) nature of these traumas or the fact that they do not co-occur with other exposures in a patterned way. Consequently, researchers should not ignore this predictor of PTSD, especially in contexts where the violence of armed conflict results in loss of life beyond those engaged in the military.

Table 7 Model Evaluation Statistics — Formal Military

\begin{tabular}{llll}
\hline & Criteria & COMBAT & COND \\
\hline $\begin{array}{llll}\text { Reliability } \\
\text { Omega }\end{array}$ & $\geq 0.7$ & 0.94 & 0.86 \\
CR & & 0.63 & 0.60 \\
Validity & & & \\
AVE & $\geq 0.5$ or $>$ CR & 0.64 & 0.63 \\
SC & AVE $>$ SC & 0.13 & 0.13 \\
Corr. W/ PTSD & p $\leq 0.05$ & $0.36^{*}$ & $0.29^{*}$ \\
\hline
\end{tabular}

However, they should assess its association with PTSD and other mental health indicators separately from other war-related traumatic events.

\section{Prior instruments and the VHAS population}

The VHAS instrument adapted questions from the NVVRS [14], DRRI [13], CES [6], and the PCL-5 while also including questions about injury to oneself, the death and injury of family members, and displacement. This unique composition of items allowed us to identify new factor structures for exposure to traumatic events and conditions in contexts of armed conflict. Prior psychometric testing of war-exposure scales identified three or more factors (depending on the scale), with varying item compositions. For example, U.S. Army and Marine Corps Mental Health Advisory Team's Combat Experiences Scale (MHAT-CES) identified exposures related to combat environment, direct engagement in combat, and nearness to severe injury or death [26]. However, they acknowledged poor discriminant validity. In other words, the three factors were not discernably distinct from one another. The DRRI identified five war-related factors, including combat experiences, the deployment environment, chemical exposures, deployment concerns, and postbattle experiences. While postbattle experiences largely map onto the MHAT-CES's nearness to death factor, the other factors diverge considerably. Like the MHAT-CES, the DRRI exhibited poor factor distinctiveness. The VHAS instrument contained items from both of the above scales, supplemented with questions from the NVVRS and questions 
about wartime displacement. We found that items from previously separate instruments clustered together for this sample, but the precise configurations varied across the civilian, formal military, and paramilitary populations (see Table 8). For example, items from separate factors or subscales, specifically, injury to oneself and exposure to dead or severely injured people, clustered together for civilian respondents. A similar set of items clustered with CES items for both formal and informal military respondents. However, displacement and inhospitable conditions clustered as separate factors for our sample, and the factors exhibited excellent discriminant validity. The restructuring of item clusters from prior scales indicates the need for scholars to draw items from a variety of sources and test factor structures for each new study context.

\section{Integrating trauma research domains}

This study integrated items previously used in two distinct trauma research domains. From studies of trauma in veterans, we incorporated nearness to death and combat exposure. From refugee studies, we included inhospitable conditions and displacement. While prior trauma research with veterans included inhospitable conditions, the studies used conditions perceived to be inhospitable to veterans of foreign wars, such as undesirable food, climate, insects, living conditions, and other chronic, low-magnitude stressors of the deployment environment. These conditions are unlikely to be perceived as inhospitable to populations residing in armed conflict locales. However, psychosocial approaches to the study of war exposure and trauma have noted the importance of "daily stressors," i.e., stressful social and material conditions, especially as exacerbated by war [65]. Our inclusion of inhospitable conditions such as shortages of food and water, the inability to sleep due to bombings and conflict, and exposure to toxic chemicals supports the findings of scholars taking a psychosocial approach. We found strong support for including these items as potentially traumatic events. Scholars have also noted that post-war "daily stressors" can affect mental health. Future studies should examine the mediating role of postwar stressors for war-exposure and mental health.

We also found support for the inclusion of displacement items, commonly incorporated in refugee studies, for both civilians and members of the informal military. For civilians, displacement clustered with exposure to toxic chemicals, functioning as a subscale within inhospitable environmental conditions, while for the informal military, displacement and inhospitable conditions clustered together in a single factor. This finding likely reflects the co-occurrence of displacement and inhospitable conditions. Prior research has found that inhospitable conditions not only precede or induce

Table 8 Comparison of Factor Structures from Prior Scales

\begin{tabular}{|c|c|c|c|c|}
\hline VHAS Items & NVVRS & CES & DDRI & MHAT-CES \\
\hline Wounded in warzone & & & Combat Exper. & Direct Engagement \\
\hline Know people who were injured & $x$ & & & \\
\hline Saw dead Vietnamese soldiers & & & Postbattle Exper. & \\
\hline Saw dead foreign soldiers & & & Postbattle Exper. & Near Injury/Death \\
\hline Saw dead civilians & & & Postbattle Exper. & \\
\hline Went on combat patrols & & $x$ & Combat Exper. & \\
\hline Was attacked/ambushed & & & Combat Exper. & Combat Envir. \\
\hline Came under artillery fire & & $x$ & Combat Exper. & Combat Envir. \\
\hline Shot at the enemy & & $x$ & Combat Exper. & Combat Envir. \\
\hline Caused death of an enemy & & & Combat Exper. & Combat Envir. \\
\hline Was nearly shot & & $x$ & & Direct Engagement \\
\hline Friend was shot near $\mathrm{R}$ & & $x$ & Combat Exper. & Direct Engagement \\
\hline Exposed to toxic chemicals & & & Chemical Exposure & \\
\hline \multicolumn{5}{|l|}{ Moved due to bombings } \\
\hline \multicolumn{5}{|l|}{ Moved due to evacuation } \\
\hline Shortage of clean water & $x$ & & & \\
\hline Food shortage & & & Deployment Env. & \\
\hline Inability to sleep & & & Deployment Env. & \\
\hline Fear of death/severe injury & & & Deploy. Concerns & \\
\hline
\end{tabular}


displacement they also occur during exile [35]. Conditions of return can also be traumatizing. A study among war survivors in Kosovo investigated why displacement was so frequently listed as a source of trauma [66]. It found that "most people became traumatised after their return to Kosovo because they found their houses and property completely or partially destroyed ... They often found that close relatives or friends had been killed or were missing" [66]. Such conditions at each stage of displacement compounded the trauma of displacement itself. These findings indicate the need for researchers to include an array of displacement items, crafting interdisciplinary instruments that draw from both veterans and refugee studies, especially when studying mixed populations (e.g., civilians, formal military, and paramilitary).

\section{Distinct approaches for separate subpopulations}

A central finding of this study is that the items capturing exposure to war-related traumatic events differ for civilians, formal military, and paramilitary. This finding is significant because prior research has not investigated paramilitary groups, such as militias or youth military organizations, as distinct subpopulations uniquely exposed to war events with unique experiences framing their perception of those events. Our analyses found distinct configurations of traumatic events for the three groups.

In interpreting the factor composition for each of these groups, contextual knowledge is critical. For the civilians in the VHAS sample, nearly all of the items available clustered together as indicators of war-related trauma exposure, with one exception: knowing people who were injured. This is best understood in comparison to members of the formal military. Civilians who knew injured people might have been less likely to be traumatized since their acquaintance(s) survived. In contrast, for the formal military, injured acquaintances were likely their fellow soldiers. As such, the members of the military may have experienced something akin to survivor's guilt or a form of moral injury for failing to prevent the injury of their acquaintance. Additionally, the daily lives of civilians were less frequently impacted by the injury of others. For soldiers, who experienced a daily barrage of diverse traumatic events, knowing others who were injured was likely a more common experience, one that punctuated their other exposures.

Participants in informal military organizations exhibited the most 'erratic' configuration of combat/violence items. Though most of the experiences related to military activities and combat duties were elements of the combat factor members of paramilitary organizations, several of the more universally experienced violence-related exposures (i.e., events also experienced by civilians), such as being wounded in the warzone and seeing dead or severely injured foreign soldiers were not. This factor composition may reflect their more limited exposure to combat. As providers of logistical support to the formal military, these respondents were certainly exposed to attacks but were less likely to engage the enemy, thus less likely to be wounded or to see wounded or deceased foreign soldiers [18]. The reduced propensity for exposure to the violent results of engagement with the enemy may increase the salience of these events as indicators of war-related trauma exposure. In contrast, for the formal military, nearly all exposures of the combat-related exposures contribute to the tapestry of war exposure, each adding to the intensity of their exposure.

Finally, while all inhospitable environmental conditions cluster together as traumatic exposures in civilians, albeit in two subfactors, only displacement, and shortages of food and water grouped in a factor for participants in the informal military. King et al. [13] and others have noted the protective effect of military training and preparedness, unit cohesion, and social support for mitigating both exposure and response to war-related traumatic events. As such, the number of inhospitable conditions comprising an inhospitable conditions dimension of war exposure is lower for members of both the informal and formal military. Moreover, for the formal military, the failure of displacement to load on a factor is not unexpected, as they were unlikely to be evacuated but highly likely to be deployed. We also suspect that fearing death failed to load on a factor for both formal and informal military since it may have been a common consequence of their duties, especially combat duties. Thus, combat experiences more accurately reflect their nuanced exposure to the traumatic events of war. Further research should investigate civilian, informal military, and formal military perceptions of their experiences to distinguish how and why the wartime stressors diverge for these groups. Ultimately, the distinct configurations of war exposure factors for these subpopulations speak to the need to recognize and individually analyze subpopulations' unique exposures to traumatic events. Specifically, in populations residing in warzones, it is crucial to understand the shades of informal military and their roles in the conflict.

One weakness of the current study relates to gender representation across military service subpopulations. In assessing exposure to war-related traumas, it may be important to consider gender as it structures the nature of exposure as well as the consequences of exposure [67]. Although the Vietnamese were heavily mobilized to join the Vietnam War effort, in the VHAS sample, women were still far less likely to be veterans than men. To compensate for gender imbalances in service, the VHAS oversampled women with military service [39]. However, female veterans were less frequently exposed to stressful military experiences than male veterans. This difference in exposure rates likely results from women fulfilling 
different military roles than men, such as women's higher prevalence in the Youth Shock Brigades as compared to the North Vietnamese Army. Future studies might further oversample women in various military positions to investigate the intersection of gender and military service and disentangle their distinctive influence upon relevant wartime stressors and the association of wartime stressors with PTSD and other health outcomes.

A second weakness of the study relates to the retrospective nature of the study. The long duration between war exposure and the respondents' reporting of these events in the VHAS may have impacted recall. Mundane details may fade over time, while some experts believe memories of traumatic events may improve over the years. However, the relationship between trauma and memory is contested and nuanced. Thus, findings based on retrospective accounts should be interpreted with caution. More complete recollections that could add event exposures to a respondent's account might shift the composition of factors and the resultant scales quantifying war exposure. Despite this limitation, this data presents a unique opportunity for researchers to examine the effects of war exposure, as remembered, on mental health decades later in life.

\section{Conclusion}

This study examined the wartime stress exposure of civilians, veterans of the formal military, and participants in informal military to develop a scale for use among diverse populations in low-income post-conflict countries, such as Vietnam. We validated two factors for each of these populations; however, the composition of these factors varied substantially across the groups.

For analysts seeking to understand the populationwide consequences of war-related trauma exposure, it is essential to incorporate existing war trauma measures drawn from multiple disciplines and develop new measures specific to the social and historical characteristics of the conflict under examination. For example, inhospitable conditions will diverge across different countries, historical eras, and stages of economic development. Additionally, scholars should consider the war tactics used in the conflicts under examination. In a study of the war in Afghanistan, where guerilla warfare tactics have also been used, many previously used questions would be relevant, but new questions might be added to address exposure to improvised explosive devices and other contemporary war tactics [68]. Specific questions related to novel forms of moral injury should also be considered. For example, in the Afghan situation, Taliban fighters regularly use civilians as human shields and disguise themselves as civilians (ibid.). Opposing military forces may repeatedly witness the death of civilians, triggering moral injury.
Finally, while the present study found support for items used in prior instruments, we also found support for new items drawn from other disciplines and items specific to the Vietnam context. We recommend that scholars seeking to measure war-related trauma include items specific to the conflict under investigation, inclusive of exposure to death and severe injury, combat experiences, forced migration, and inhospitable conditions, and with particular attention to subgroups for whom these traumatic exposures might function differently, as they have for the subgroups in our study. This study has contributed to our understanding of diverse wartime experiences, improving our understanding of war-related trauma in the Vietnam context, offering insights for other contexts. Gender, military service, and other social statuses structure exposure to war trauma and reactions to that exposure. Understanding the experiences of distinct subpopulations improves our ability to discern the nature of trauma exposure and craft interventions that address the health and wellbeing of all members of the population.

\section{Supplementary Information}

The online version contains supplementary material available at https:/doi. org/10.1186/s13031-021-00343-y.

\section{Additional file 1. Appendices.}

\section{Abbreviations \\ APA: American Psychiatric Association; AVE: Average variance extracted; CES: Combat Exposure Scale; CFA: Confirmatory factor analysis; \\ CFI: Comparative fit index; CR: Composite factor reliability; DRRI: Deployment Risk and Resilience Inventory; DSM-5: Diagnostic and Statistical Manual of Mental Disorders - 5th Edition; EFA: Exploratory factor analysis; IPF: Iterated principal factors; GOF: Goodness of fit; KMO: Kaiser-Meyer-Okin; MHAT- CES: Mental Health Advisory Team's Combat Experiences Scale; NWR S: National Vietnam Veterans Readjustment Study; PCL-5: PTSD Checklist for DSM-5; PTSD: Postraumatic stress disorder; RMSEA: Root mean squared error of approximation; SC: Squared correlations between factors; \\ SRMR: Standardized root mean squared residual; TNXP: Thanh niên xung phong (Youth Shock Brigades); VHAS: Vietnam Health and Aging Study}

\section{Acknowledgements}

The authors would like to thank Kathryn Fraser, Dr. Colleen James, Dr. Daniel Adkins, and the anonymous reviewers for their valuable assistance on earlier drafts of this paper.

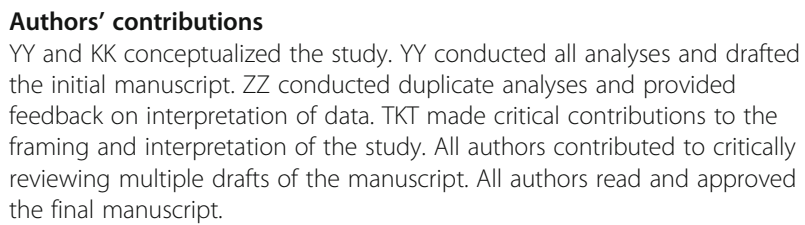

Funding

This study was funded by the National Institutes of Health/National Institute on Aging (R01 AG052537).

\section{Availability of data and materials}

The dataset used in the current study are available from the authors upon reasonable request and with completion of data user agreement. 


\section{Ethics approval and consent to participate}

Ethics approval for the current study was obtained from the University of Utah's Institutional Review Board (IRB_00099861), Mount Saint Vincent University's Research Ethics Board (2018-047), Hanoi Medical University's Independent Review Board in Bio-medical Research (IRB No. 00003121), and Vietnam's Ministry of Health.

\section{Consent for publication}

Not applicable.

\section{Competing interests}

The authors declare that they have no competing interests.

\section{Author details}

${ }^{1}$ Department of Sociology, University of Utah, Salt Lake City, UT, USA. ${ }^{2}$ Global Aging and Community Initiative, Mount Saint Vincent University, Halifax, Nova Scotia, Canada. ${ }^{3}$ Family Medicine Department, Hanoi Medical University, Hanoi, Vietnam.

\section{Received: 17 September 2020 Accepted: 26 January 2021} Published online: 06 March 2021

\section{References}

1. Bedard K, Deschênes $O$. The long-term impact of military service on health: evidence from world war II and Korean war veterans. Am Econ Rev. 2006; 96(1):176-94.

2. Levy BS, Sidel WW. War and public health. USA: Oxford University Press; 2008.

3. Spiro A, Settersten RA. Long-term implications of military Service for LaterLife Health and Well-Being. Res Hum Dev. 2012;9(3):183-90.

4. de Jong JTVM. Lifetime events and posttraumatic stress disorder in 4 Postconflict settings. JAMA. 2001;286(5):555.

5. Fontana A, Rosenheck R. Model of war zone stressors and posttraumatic stress disorder. J Trauma Stress. 1999;12(1):111-26.

6. Keane TM, Fairbank JA, Caddell JM, Zimmering RT, Taylor KL, Mora CA. Clinical evaluation of a measure to assess combat exposure. Psychol Assess J Consult Clin Psychol. 1989;1(1):53-5.

7. Durai UNB, Chopra MP, Coakley E, Llorente MD, Kirchner JE, Cook JM, et al. Exposure to trauma and posttraumatic stress disorder symptoms in older veterans attending primary care: comorbid conditions and self-rated health status. J Am Geriatr Soc. 2011;59(6):1087-92.

8. Gallers J, Foy DW, Donahoe CP, Goldfarb J. Post-traumatic stress disorder in Vietnam combat veterans: effects of traumatic violence exposure and military adjustment. J Trauma Stress. 1988;1(2):181-92.

9. Johnson AM, Rose KM, Elder GH Jr, Chambless LE, Kaufman JS, Heiss G. Military combat and risk of coronary heart disease and ischemic stroke in aging men: the atherosclerosis risk in communities (ARIC) study. Ann Epidemiol. 2010;20(2):143-50.

10. Nichter B, Norman S, Haller M, Pietrzak R. Physical health burden of PTSD, depression, and their comorbidity in the U.S. veteran population: morbidity, functioning, and disability. J Psychosom Res. 2019;124(109744):1-7.

11. OToole BI, Catts SV. Trauma, PTSD, and physical health: an epidemiological study of Australian Vietnam veterans. J Psychosom Res. 2008;64:33-40

12. Kimbrel NA, Evans LD, Patel AB, Wilson LC, Meyer EC, Gulliver SB, et al. The critical warzone experiences (CWE) scale - initial psychometric properties and association with PTSD, anxiety, and depression. Psychiatry Res. 2014; 220(3):1118-24.

13. King LA, King DW, Vogt DS, Knight J, Samper RE. Deployment risk and resilience inventory: a collection of measures for studying deploymentrelated experiences of military personnel and veterans. Mil Psychol. 2006; 18(2):89-120.

14. Kulka RA, Schlenger WE, Fairbank JA, Hough RL, Jordan BK, Marmar CR, et al. Contractual report of findings from the National Vietnam Veterans Readjustment Study. Research Triangle Park, NC: Research Triangle Institute; 1988. p. 1-682.

15. Laufer RS, Gallops MS, Frey-Wouters E. War stress and trauma: the Vietnam veteran experience. J Health Soc Behav. 1984;25(1):65-85.

16. Fodor KE, Unterhitzenberger J, Chou C-Y, Kartal D, Leistner S, Milosavljevic $M$, et al. Is traumatic stress research global? A bibliometric analysis. Eur J Psychotraumatol. 2014;5(1):23269-8.
17. Roelfs D, Shor E, Davidson K, Schwartz J. War-related stress exposure and mortality: a meta-analysis. Int J Epidemiol. 2010;39(6):1499-509.

18. Guillemot F. Death and suffering at first hand: youth shock brigades during the Vietnam war (1950--1975). J Vietnam Stud. 2009:4(3):17-60.

19. American Psychiatric Association. Trauma [Internet]. American Psychiatric Association. 2019. Available from: https://www.apa.org/topics/trauma/

20. Green BL. Defining trauma: terminology and generic stressor Dimensions1. J Appl Soc Psychol. 1990;20(20):1632-42.

21. Keane TM. Defining traumatic stress: some comments on the current terminological confusion. Behav Ther. 1985;16(4):419-23.

22. Weathers FW, Keane TM. The criterion a problem revisited: controversies and challenges in defining and measuring psychological trauma. J Trauma Stress. 2007;20(2):107-21.

23. Charak R, Armour C, Elklit A, Angmo D, Elhai JD, Koot HM. Factor structure of PTSD, and relation with gender in trauma survivors from India. Eur J Psychotraumatol. 2014;5(1):1-11.

24. American Psychiatric Association. Trauma- and Stressor-Related Disorders. In: Fifth Edition. Arlington, VA: American Psychiatric Association; 2014. Available from: https://dsm.psychiatryonline.org/doi/full/https://doi.org/10.1176/appi. books.9780890425596.dsm07\#BABJAEHE

25. King DW, King LA, Gudanowski DM, Vreven DL. Alternative representations of war zone stressors: relationships to posttraumatic stress disorder in male and female Vietnam veterans. J Abnorm Psychol. 1995;104(1): 184-96.

26. Guyker WM, Donnelly K, Donnelly JP, Dunnam M, Warner GC, Kittleson J, et al. Dimensionality, reliability, and validity of the combat experiences scale. Mil Med. 2013;178(4):377-84.

27. Hoge CW, Castro CA, Messer SC, McGurk D, Cotting DI, Koffman RL. Combat duty in Iraq and Afghanistan, mental health problems, and barriers to care. N Engl J Med. 2004;351(1):13-22.

28. Drescher KD, Foy DW. When they come home: posttraumatic stress, moral injury, and spiritual consequences for veterans. Reflective Pract Form Superv Minist. 2008;28:85-102.

29. Litz BT, Stein N, Delaney E, Lebowitz L, Nash WP, Silva C, et al. Moral injury and moral repair in war veterans: a preliminary model and intervention strategy. Clin Psychol Rev. 2009;29(8):695-706.

30. Griffin BJ, Purcell N, Burkman K, Litz BT, Bryan CJ, Schmitz M, et al. Moral injury: an integrative review. J Trauma Stress. 2019;32(3):350-62.

31. Grady DA, Woolfolk RL, Budney AJ. Dimensions of war zone stress. An empirical analysis. J Nerv Ment Dis. 1989;177(6):347-50.

32. Bell V, Méndez F, Martínez C, Palma PP, Bosch M. Characteristics of the Colombian armed conflict and the mental health of civilians living in active conflict zones. Confl Health. 2012;6(1):10.

33. Hauff $E$, Vaglum P. Organised violence and the stress of exile: predictors of mental health in a community cohort of Vietnamese refugees three years after resettlement. Br J Psychiatry. 1995;166(3):360-7.

34. Siriwardhana C, Ali SS, Roberts B, Stewart R. A systematic review of resilience and mental health outcomes of conflict-driven adult forced migrants. Confl Health. 2014;8(1):1-14.

35. Porter M, Haslam N. Predisplacement and Postdisplacement factors associated with mental health of refugees and internally displaced persons: a meta-analysis. JAMA. 2005;294(5):602.

36. Clodfelter M. Vietnam in military statistics: a history of the Indochina wars, 1772-1991. Jefferson, North Carolina: McFarland \& Company; 1995.

37. Weisner LA. Victims and survivors: displaced persons and other war victims in Vietnam, 1954-1975. Westport, CT: Greenwood Press; 1988.

38. Rottman GL. North Vietnamese Army soldier 1958-1975. Bloomsbury Press; 2012.

39. Korinek K, Teerawichitchainan B, Zimmer Z, Brindle E, Nguyen TKC, Nguyen $\mathrm{HM}$, et al. Design and measurement in a study of war exposure, health, and aging: protocol for the Vietnam health and aging study. BMC Public Health. 2019;19(1):1-11.

40. Miguel E, Roland G. The long-run impact of bombing Vietnam. J Dev Econ. 2011;96(1):1-15.

41. Lang AJ, Wilkins K, Roy-Byrne PP, Golinelli D, Chavira D, Sherbourne C, et al. Abbreviated PTSD checklist (PCL) as a guide to clinical response. Gen Hosp Psychiatry. 2012;34(4):332-8.

42. Lang AJ, Stein MB. An abbreviated PTSD checklist for use as a screening instrument in primary care. Behav Res Ther. 2005:43(5):585-94.

43. Price M, Szafranski DD, van Stolk-Cooke K, Gros DF. Investigation of abbreviated 4 and 8 item versions of the PTSD checklist 5. Psychiatry Res. 2016;239:124-30. 
44. Brown TA. Confirmatory Factor Analysis for Applied Research. Second. New York: Guilford Press; 2015. (Little TD, editor. Methodology in the Social Sciences).

45. Bernstein $\mathbb{H}$, Teng $\mathrm{G}$. Factoring items and factoring scales are different: spurious evidence for multidimensionality due to item categorization. Psychol Bull. 1989;105(3):467-77.

46. Fabrigar LR, Wegener DT, MacCallum RC, Strahan EJ. Evaluating the use of exploratory factor analysis in psychological research. Psychol Methods. 1999; 4(3):272-99.

47. Osborne JW. Best Practices in Exploratory Factor Analysis. Scotts Valley: CA: CreateSpace Independent Publishing; 2014. 1-77 p.

48. StataCorp. Stata 15 Base Reference Manual. College Station, TX: Stata Press; 2017.

49. Harman HH. Modern factor analysis. 3rd ed. Chicago: University of Chicago Press; 1976.

50. DeVellis RF. Scale development: theory and applications. Fourth ed. Thousand Oaks, CA: SAGE Publications; 2017. 280 p.

51. Price LR. Psychometric methods: theory into practice. New York: Guilford Press; 2017

52. Velicer WF, Jackson DN. Component analysis versus common factor analysis: some further observations. Multivar Behav Res. 1990;25(1):97-114.

53. Tabachnick BG, Fidell LS. Principal components and factor analysis. In: Using Multivariate Statistics. 7th ed. N Y; 2019. p. 476-527.

54. Yu C-Y. Evaluating cutoff criteria of model fit indices for latent variable models with binary and continuous outcomes. Los Angeles: University of California; 2002.

55. Hu LT, Bentler PM. Cutoff criteria for fit indexes in covariance structure analysis: conventional criteria versus new alternatives. Struct Equ Model Multidiscip J. 2009;6(1):1-55.

56. Padilla MA, Divers J. A comparison of composite reliability estimators. Educ Psychol Meas. 2015;76(3):436-53.

57. Fornell C, Larcker DF. Structural equation models with unobservable variables and measurement error: algebra and statistics. J Mark Res. 1981; 18(3):382-8.

58. Anderson JC, Gerbing DW. Structural equation modeling in practice: a review and recommended two-step approach. Psychol Bull. 2004;103(3): 411-23.

59. Cunningham WA, Preacher KJ, Banaji MR. Implicit attitude measures: consistency, stability, and convergent validity. Psychol Sci. 2001;12(2):163-70.

60. Netemeyer RG, Bearden WO, Sharma S. Scaling procedures: issues and applications. Thousand Oaks: SAGE Publications; 2003. 224 p.

61. Costello AB, Osborne JW. Best practices in exploratory factor analysis: four recommendations for getting the Most from your analysis. Pract Assess Res Eval. 2005;10(7):1-9.

62. Chen F, Bollen KA, Paxton P, Curran PJ, Kirby JB. Improper solutions in structural equation models: causes, consequences, and strategies. Sociol Methods Res. 2001;29(4):468-508.

63. Heptinstall E, Sethna V, Taylor E. PTSD and depression in refugee children: associations with pre-migration trauma and post-migration stress. Eur Child Adolesc Psychiatry. 2004;13(6):373-80.

64. Wilson JP, Smith WK, Johnson SK. A comparative analysis of PTSD among various survivor groups. In: Figley CR, editor. Trauma And Its Wake. Routledge; 2013.

65. Miller KE, Rasmussen A. War exposure, daily stressors, and mental health in conflict and post-conflict settings: bridging the divide between traumafocused and psychosocial frameworks. Soc Sci Med. 2010;70(1):7-16.

66. Wang S-J, Salihu M, Rushiti F, Bala L, Modvig J. Survivors of the war in the northern Kosovo: violence exposure, risk factors and public health effects of an ethnic conflict. Confl Health. 2010;4(1):11.

67. Korinek K, Yvette Y, Bussarawan T, Nguyen T, Kim C, Miles K, Zachary Z. Is War Hard on the Heart? Gender, Wartime Stress and Late Life Cardiovascular Conditions in a Population of Vietnamese Older Adults. Soc Sci Med. 2020; 265:113380.

68. Arnoldy B. In Afghanistan, Taliban kills more civilians than US. Christian Science Monitor. 2009; Available from: https://www.csmonitor.com/World/ Asia-South-Central/2009/0731/p06s15-wosc.htm

\section{Publisher's Note}

Springer Nature remains neutral with regard to jurisdictional claims in published maps and institutional affiliations.

\section{Ready to submit your research? Choose BMC and benefit from:}

- fast, convenient online submission

- thorough peer review by experienced researchers in your field

- rapid publication on acceptance

- support for research data, including large and complex data types

- gold Open Access which fosters wider collaboration and increased citations

- maximum visibility for your research: over $100 \mathrm{M}$ website views per year

At BMC, research is always in progress.

Learn more biomedcentral.com/submissions 